\title{
Rapid quantification of hepatitis $B$ virus DNA by direct real-time PCR from serum without DNA extraction
}

\author{
Correspondence \\ Zheng-jiang Cheng \\ zjcheng11@yahoo.com.cn
}

Received 8 January 2007

Accepted 11 February 2007
Zheng-Jiang Cheng, ${ }^{1,2}$ Li-Hua Hu, ${ }^{1}$ Wen-Rong $\mathrm{Fu}^{3}$ and Yi-Rong $\mathrm{Li}^{1}$

${ }^{1}$ Clinical Laboratory Medicine Department, Union Hospital, Tongji Medical College, Huazhong University of Science and Technology, Wuhan 430022, People's Republic of China

${ }^{2}$ Clinical Laboratory Medicine Department, Xiangfan Hospital, Tongji Medical College, Huazhong University of Science and Technology, Xiangfan 441021, People's Republic of China

${ }^{3}$ Pathology Department, Xiangfan Hospital, Tongji Medical College, Huazhong University of Science and Technology, Xiangfan 441021, People's Republic of China

\begin{abstract}
The purpose of this study was to quantify hepatitis B virus DNA by direct real-time PCR from serum without the need for DNA extraction. Crossing point (Cp) values were determined automatically using the second derivative maximum mode. Since serum samples from patients are inevitably haemolysed, lipaemic or icteric, the interference of endogenous substances from the serum in real-time PCR was evaluated. The result showed that, although serum protein quenched the intensity of fluorescence, the $\mathrm{Cp}$ value adopted to calculate the quantity of DNA copies remained unchanged. Importantly, real-time PCR from serum with or without DNA extraction reached a high level of concordance. This direct serum PCR method without the DNA extraction and gel electrophoresis allows for substantial labour and cost savings. In addition, it is also suitable for rapid DNA quantification during clinical diagnosis.
\end{abstract}

\section{INTRODUCTION}

Although classical PCR-based assays have increased the sensitivity of analyses, their application in clinical practice is hindered by technical complexity, susceptibility to contamination and variable reproducibility (Kaneko et al., 1990; Quint et al., 1995). Recent advances in PCR technology allow continuous measurement of the fluorescence emitted during amplicon production after each PCR cycle. This is achieved using a variety of different fluorescent chemistries that correlate PCR product concentration to fluorescence intensity (Higuchi et al., 1993). Reactions are characterized by the time point (or PCR cycle) where target amplification is first detected. This value is usually referred to as the cycle threshold $(\mathrm{Ct})$ or crossing point $(\mathrm{Cp})$, the time at which fluorescence intensity is significantly greater (usually ten times the SD of the baseline) than background fluorescence $\left(\mathrm{F}_{0}\right)$. Consequently, the greater the quantity of target DNA in the starting material, the faster a significant increase in fluorescence signal will appear, yielding a lower Ct (Heid et al., 1996). There are many benefits of using real-time PCR over other methods to quantify target DNA. It can produce

Abbreviations: $\mathrm{Cp}$, crossing point; $\mathrm{Ct}$, cycle threshold; $\mathrm{CV}$, coefficient of variation; $F_{P}$, fluorescence at the plateau phase; $F_{0}$, background fluorescence. quantitative data with an accurate dynamic range of 7 to $8 \log$ orders of magnitude and does not require postamplification manipulations. To date, real-time PCR is widely used in research and clinical practice (Kaltenboeck \& Wang, 2005; Espy et al., 2006; Schuler \& Dolken, 2006).

If real-time PCR is properly designed, the efficiency coefficient is close to the theoretical value of 1 (Livak \& Schmittgen, 2001), indicating that errors due to the PCR amplification process are very low. The most common causes of error are the DNA extraction procedures, a key step for real-time PCR, because any error will be amplified exponentially during the PCR process. DNA extraction efficiency varied from kit to kit and test to test, and the extraction process not only was time consuming but also tended to increase the risk of carry-over contamination. Direct PCR without DNA extraction for qualitative use has been reported in several studies (Castley et al., 2005; Ieamkhang et al., 2005). In the present study, our aim was to quantify human hepatitis B virus (HBV) DNA by direct real-time PCR from serum without a DNA extraction procedure. Since haemolysed, lipaemic and icteric serum samples from patients are inevitable in clinical practice, we evaluated the interference of these endogenous substances (also known as the serum index), including conjugated bilirubin, haemoglobin and triglycerides (Powers et al., 1986), in real-time PCR. 


\section{METHODS}

Blood samples and standards. The present study was performed with the consent of an ethics committee, as well as with the patient's consent. Serum samples were collected from 91 patients who were $\mathrm{HBsAg}^{+}$(hepatitis B surface antigen positive), and 23 healthy blood donors who were $\mathrm{HBsAg}^{-}$and anti- $\mathrm{HBc}^{-}$(anti-hepatitis B core negative). $\mathrm{HBsAg}^{+}$patients were randomly included from chronic HBV carriers attending follow-up sessions for serial monitoring of liver status. Blood samples were centrifuged within $4 \mathrm{~h}$ to obtain serum fractions, which were then divided into aliquots and kept at $-80{ }^{\circ} \mathrm{C}$ prior to testing. Serological tests for HBsAg were performed with a commercial microparticle enzyme immunoassay (CI8200; Abbott Laboratories). HBV DNA standards were included in the commercial kit (Roche Diagnostics) with HBV DNA concentrations of $5.0 \times 10^{4}, 5.0 \times 10^{5}, 5.0 \times 10^{6}$ and $5.0 \times 10^{7}$ copies $\mathrm{ml}^{-1}$.

DNA template preparation. Nucleic acid was extracted with a commercial kit (Roche Diagnostics), following the manufacturer's instructions. A $100 \mu \mathrm{l}$ volume of serum was precipitated with $100 \mu \mathrm{l}$ reagent $A$, and then centrifuged at $11336 \mathrm{~g}$ for $10 \mathrm{~min}$. The pellet was resuspended with $25 \mu \mathrm{l}$ reagent $\mathrm{B}$, heated to $100{ }^{\circ} \mathrm{C}$ for $10 \mathrm{~min}$ and spun again at $11336 \mathrm{~g}$ for $10 \mathrm{~min}$. The supernatant was used as a source of DNA for PCR.

Real-time PCR. Real-time PCR kits were obtained from Roche Diagnostics. PCR was performed using a Roche Diagnostics LightCycler and the fluorescent signal of PCR products after each cycle was monitored continuously with a fluorescent hydrolysis probe (TaqMan), according to the manufacturer's instructions. Primer sequences used for HBV were $5^{\prime}$-ACTCGTGGTGGACTTCTCTCAA$3^{\prime}$ and $3^{\prime}$-AAGAAGATGAGGCATAGCAGCA-5', and for the TaqMan probe were $5^{\prime}$-TGGATGTGTCTGCGGCGTTTTATCAT-3'. An aliquot of $2 \mu \mathrm{l}$ serum or extracted nucleic acid template was mixed with $18 \mu \mathrm{l}$ reaction mixture, and then added to the capillary. All capillaries were sealed and briefly centrifuged before amplification in the LightCycler. The PCR protocol consisted of 45 cycles of $30 \mathrm{~s}$ denaturation at $95{ }^{\circ} \mathrm{C}$, and $20 \mathrm{~s}$ annealing and extension at $60{ }^{\circ} \mathrm{C}$. The temperature transition rate was $20^{\circ} \mathrm{C} \mathrm{s}^{-1}$ for all steps. Fluorescence data were acquired once each cycle at the end of the annealing phase with a detection channel setting of F2/F1.

The influence of serum protein on real-time PCR. To evaluate the influence of serum protein on real-time PCR, we treated the standards (since the standard in HBV viral particle form was not available) with serial diluted serum protein from 5.0 to $50 \mathrm{~g} \mathrm{l}^{-1}$ and observed how the fluorescence and Cp changed.
Interference study. Since sera from patients contained endogenous substances, we studied their interference in real-time PCR. According to the protocol described in National Committee for Clinical Laboratory Standards guidance document EP7-P, the maximum concentrations of endogenous substances used in the interference test were: $240 \mu \mathrm{mol}$ conjugated bilirubin $1^{-1}, 4.0 \mathrm{~g}$ haemoglobin $1^{-1}$ and $5.0 \mathrm{mmol}$ triglycerides $1^{-1}$ (Powers et al., 1986). Interference tests were performed in duplicate using HBV DNA standards and serum specimens.

Data analysis. For data analysis, baseline adjustment was carried out in the 'proportional' mode and fluorescence curve analyses were carried out in the 'fit points' or 'second derivation maximum' mode of the LightCycler. Positive results obtained for the real-time PCR assay using fluorescent hydrolysis probe were characterized by a sigmoid curve, showing an initial rapid exponential increase in fluorescence signal followed by a plateau. Negative reactions did not show any increase in fluorescence signal. A standard curve was created automatically with the LightCycler software in each run by plotting the Ct (or Cp) number against the copy numbers of each standard, and quantification of HBV DNA for unknown samples was inferred from the regression line.

Statistics. All statistical analyses were performed with the SPSS 11.0 software package for Windows (SPSS). Comparison between the innovative method and the classical one was by $\chi^{2}$ test. A two-tailed $P$ value less than 0.05 was considered statistically significant.

\section{RESULTS}

\section{The dynamic characteristics of direct real-time PCR}

In this study, direct real-time PCR refers to the real-time PCR performed on unextracted serum. The direct real-time PCR curve was generally of log or sigmoid shape, with a slightly clockwise shift that was similar to the normal realtime PCR curve (Higuchi et al., 1993) (Fig. 1). It also indicated that the PCR kinetics consist of an early ground phase, exponential growth phase, linear growth phase and plateau phase. Serum matrix raised the $\mathrm{F}_{0}$, and this effect was attenuated gradually along with the cycle increment until positive amplification occurred. Taking an $\mathrm{HBsAg}^{+}$ serum specimen with $73.2 \mathrm{~g}$ total protein $\mathrm{l}^{-1}$, for example,

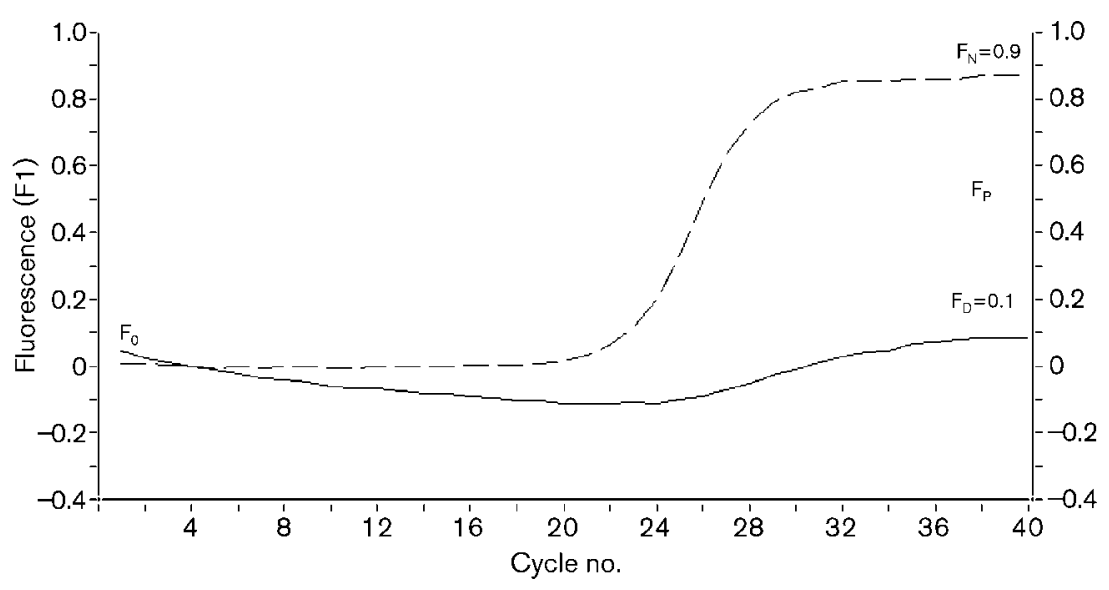

Fig. 1. The dynamic characteristics of direct real-time PCR and normal real-time PCR. An $\mathrm{HBsAg}^{+}$serum specimen with $73.2 \mathrm{~g}$ total protein $\mathrm{I}^{-1}$ was analysed by both direct (solid line) and normal (dashed line) PCR. Serum matrix raised the $F_{0}$, and the value of $F_{P}$ of direct real-time PCR kinetics was only about $10 \%$ of that acquired from normal real-time PCR. $\mathrm{F}_{\mathrm{D}} /\left(\mathrm{F}_{\mathrm{N}}-\mathrm{F}_{\mathrm{D}}\right)=0.1 /(0.9-0.1)=12.5 \%$, where $F_{D}$ is the fluorescence of direct real-time $\mathrm{PCR}$ and $\mathrm{F}_{\mathrm{N}}$ is the fluorescence of normal realtime PCR. 


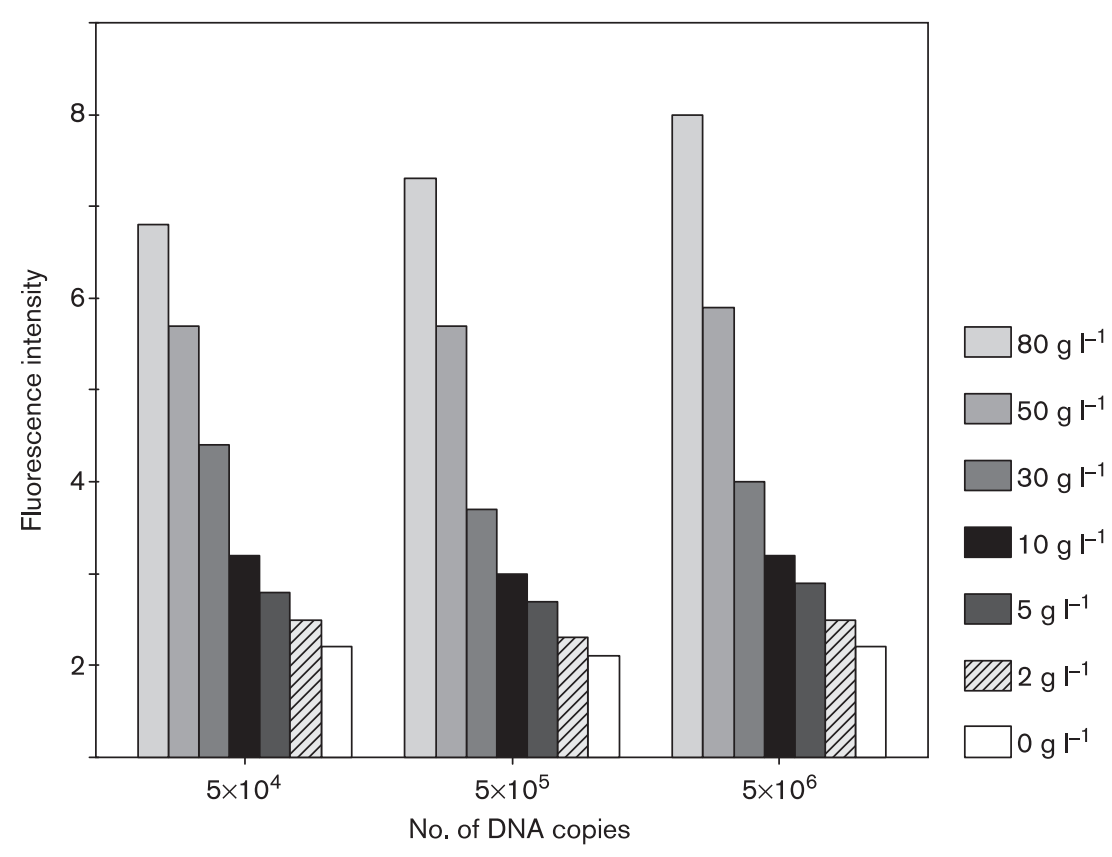

Fig. 2. Serum protein raised the $F_{0}$ in a concentration-dependent way. Three concentrations of HBV DNA of $5.0 \times 10^{4}, 5.0 \times 10^{5}$ and $5.0 \times 10^{6}$ copies $\mathrm{ml}^{-1}$ were used to assess interference in a real-time PCR assay. The concentrations of serum protein used for interference were: $80,50,30,10,5,2$ and $0 \mathrm{~g} \mathrm{I}^{-1}$. the value of fluorescence at the plateau phase $\left(\mathrm{F}_{\mathrm{P}}\right)$ of direct real-time PCR kinetics was only about $10 \%$ of that acquired from normal real-time PCR (Fig. 1). This case is representative of all the clinical specimens, which usually had total protein ranging from 60 to $80 \mathrm{~g} \mathrm{l}^{-1}$. Fluorescence values of all negative and some positive reactions were always under the baseline. This made it difficult to do baseline adjustment and crossing line setting, so fit point mode was not suitable for $\mathrm{Ct}$ number determination. We used second derivative maximum mode for Cp determination. Neither baseline adjustment nor crossing line setting was required in this method, because the software automatically determined the $\mathrm{Cp}$ value by identifying the first turning point of the fluorescence curve.

\section{The influence of serum protein on real-time PCR}

Serum protein raised the $\mathrm{F}_{0}$ (Fig. 2) and decreased the $\mathrm{F}_{\mathrm{P}}$ in a concentration-dependent way (Fig. 3), but the $\mathrm{Cp}$ remained unchanged (Table 1 ).

\section{Interference study}

All the tested endogenous substances (conjugated bilirubin, haemoglobin and triglycerides) slightly decreased the initial $\mathrm{F}_{0}$ in a concentration-dependent way. The substances also decreased the $\mathrm{F}_{\mathrm{P}}$ of direct real-time PCR kinetics, although $\mathrm{Cp}$ values remained unchanged (Table 1 ). The $\mathrm{Cp}$ of realtime PCR had a good reproducibility even at a relative

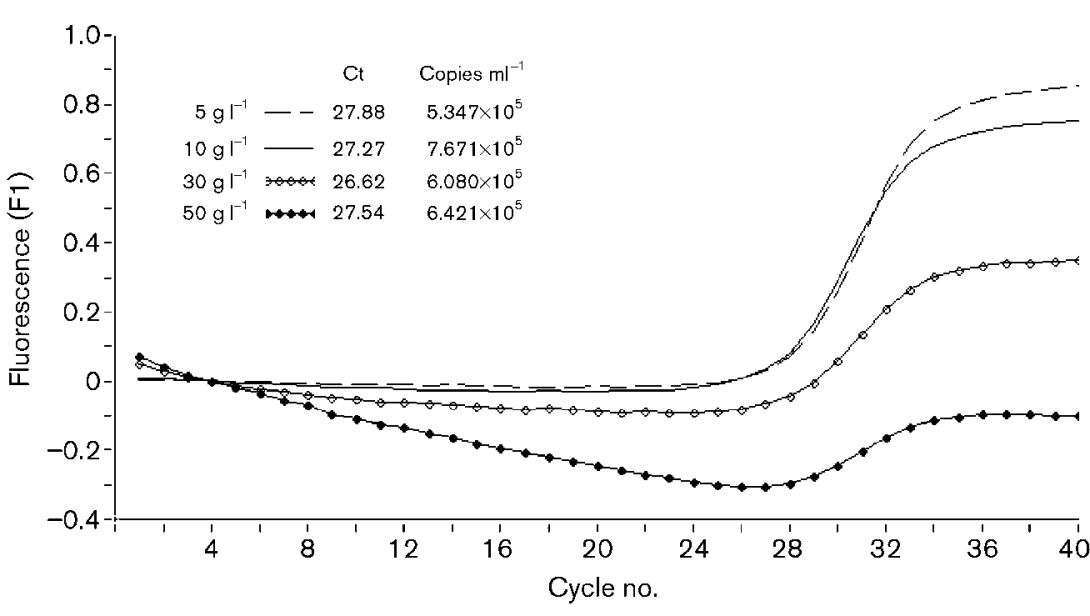

Fig. 3. The dynamic characteristics of real-time PCR with serial diluted serum protein. Samples of DNA $\left(5.0 \times 10^{5}\right.$ copies $\left.\mathrm{ml}^{-1}\right)$ mixed with equal amounts of serial diluted serum protein from 5.0 to $50 \mathrm{~g} \mathrm{I}^{-1}$ yielded almost the same $\mathrm{Cp}$. The presence of serum protein lowered the $F_{P}$ of the DNA sample proportionately. 
Table 1. Fluorescence and $\mathrm{Cp}$ interference by serum endogenous substances

The differences of $F_{P}$ in each group of endogenous substances are statistically significant $(P<0.05)$.

\begin{tabular}{|c|c|c|c|c|c|c|c|c|c|c|c|c|c|c|}
\hline & \multirow{2}{*}{$\begin{array}{l}\text { No. of DNA } \\
\text { copies } \mathrm{ml}^{-1}\end{array}$} & \multicolumn{4}{|c|}{ Serum protein $\left(\mathrm{g} \mathrm{l}^{-1}\right)$} & \multicolumn{3}{|c|}{ Haemoglobin $\left(\mathrm{g} \mathrm{l}^{-1}\right)$} & \multicolumn{3}{|c|}{ Bilirubin $\left(\mu \mathrm{mol} \mathbf{l}^{-1}\right)$} & \multicolumn{3}{|c|}{ Triglyceride $\left(\mathrm{mmol} \mathrm{l}^{-1}\right)$} \\
\hline & & 0 & 10 & 50 & 80 & 0.8 & 1.6 & 4.0 & 20 & 60 & 180 & 1 & 2 & 5 \\
\hline \multirow{3}{*}{$\mathrm{F}_{\mathrm{P}}(\%)$} & $5 \times 10^{5}$ & 94.7 & 75.6 & 18.4 & 12.8 & 14.5 & 10.2 & 7.0 & 17.1 & 15.2 & 9.2 & 20.3 & 16.6 & 15.6 \\
\hline & $5 \times 10^{6}$ & 98.0 & 77.4 & 20.9 & 13.7 & 14.5 & 12.1 & 7.0 & 19.4 & 15.2 & 11.3 & 18.7 & 16.6 & 16.6 \\
\hline & $5 \times 10^{7}$ & 100 & 84.7 & 25.5 & 20.3 & 16.0 & 14.5 & 8.0 & 19.4 & 16.1 & 14.4 & 18.7 & 17.2 & 16.6 \\
\hline \multirow{3}{*}{$\mathrm{Cp}$} & $5 \times 10^{5}$ & 27.2 & 27.3 & 27.5 & 27.4 & 27.6 & 27.5 & 28.2 & 28.0 & 28.4 & 28.3 & 27.2 & 27.0 & 27.6 \\
\hline & $5 \times 10^{6}$ & 24.5 & 24.5 & 25.0 & 25.1 & 24.1 & 24.1 & 24.6 & 24.6 & 24.6 & 25.8 & 24.8 & 24.9 & 24.7 \\
\hline & $5 \times 10^{7}$ & 20.9 & 20.8 & 21.0 & 21.2 & 19.8 & 20.6 & 20.8 & 21.0 & 21.5 & 22.5 & 20.2 & 20.9 & 21.7 \\
\hline
\end{tabular}

fluorescence as low as $6 \%$. Bilirubin decreased the fluorescence value to an undetectable baseline when it was present in concentrations above $240 \mu \mathrm{mol}^{-1}$.

\section{Performance characteristics and efficiency}

The performance of the direct real-time PCR method was determined from $\mathrm{Cp}$ values obtained with HBV DNA standards and known samples (known samples were diluted tenfold from $10^{7}$ to $10^{2}$ copies $\mathrm{ml}^{-1}$ ). All calibration curves showed linearity over the entire quantification range with a correlation coefficient $>0.99$, indicating a precise log-linear relationship. The linear correlation between the cycle number $(y)$ and the input concentration (copies per reaction) of HBV DNA template for classical real-time PCR and direct real-time PCR were $y=-3.504$ $\log _{10} x+47.89(r=-1.00)$ and $y=-3.569 \log _{10} x+46.63$ $(r=-1.00)$. Calculated according to the literature, the amplification efficiencies were 93.0 and $90.6 \%$, respectively. When known samples were diluted to $2 \times 10^{2}$ copies $\mathrm{ml}^{-1}$, they could still be detected in the presence of serum protein. Pooled positive serum was tested 20 times using both methods, giving intra-assay coefficients of variation (CVs) of 5.4 to $1.6 \%$, and inter-assay CVs of 6.5 to $2.3 \%$, respectively, for real-time PCR with (normal/classical) and without (direct) DNA extraction (Table 2).
To determine the clinical performance of direct serum realtime PCR, HBV DNA concentrations were measured in serum samples from $91 \mathrm{HBsAg}^{+}$patients as well as 23 healthy controls. Results were compared to those determined by classical real-time PCR. Taking $1.0 \times 10^{3}$ copies $\mathrm{ml}^{-1}$ as the positive threshold, the seroprevalance of $\mathrm{HBV}$ DNA among $\mathrm{HBsAg}^{+}$patients was $65.6 \%$ (63/91) by both methods. The rates of positive conformability and negative conformability between the two methods were both $100 \%$. The log-transformed HBV DNA concentrations of 63 samples between the two methods demonstrated a good correlation (Fig. 4; $r^{2}=0.863 ; P<0.001$ ). All 23 healthy controls tested negative by both methods, yielding a specificity rate of $100 \%$.

\section{DISCUSSION}

The TaqMan hydrolysis probe, which is labelled at its $5^{\prime}$ end with a fluorochrome, emits fluorescent light upon hydrolysis allowing detection of PCR product accumulation. This sequence-specific probe is labelled with a reporter dye on the $5^{\prime}$ end and a quencher dye on the $3^{\prime}$ end, which allows the quencher to reduce the reporter fluorescence intensity by fluorescence resonance energy transfer when the probe is intact. When annealed to the

Table 2. Comparison of the two real-time PCR methods

\begin{tabular}{|lcc|}
\hline & Real-time PCR & Direct real-time PCR \\
\hline Log-linear relationship & & \\
Slope & -3.504 & -3.569 \\
Intercept & 47.89 & 46.63 \\
Amplification efficiency & 0.93 & 0.91 \\
Cp reproducibility $(\boldsymbol{n}=\mathbf{2 0})$ & & $27.63 \pm 0.45(1.6 \%)$ \\
Intra-assay, mean \pm SD $[\mathrm{CV}(\%)]$ & $27.14 \pm 1.46(5.4 \%)$ & $27.36 \pm 0.64(2.3 \%)$ \\
Inter-assay, mean \pm SD $[\mathrm{CV}(\%)]$ & $27.41 \pm 1.78(6.5 \%)$ & No \\
DNA extraction & Yes & 1.0 \\
Performance time $(\mathrm{h})$ & 2.0 & \\
\hline
\end{tabular}




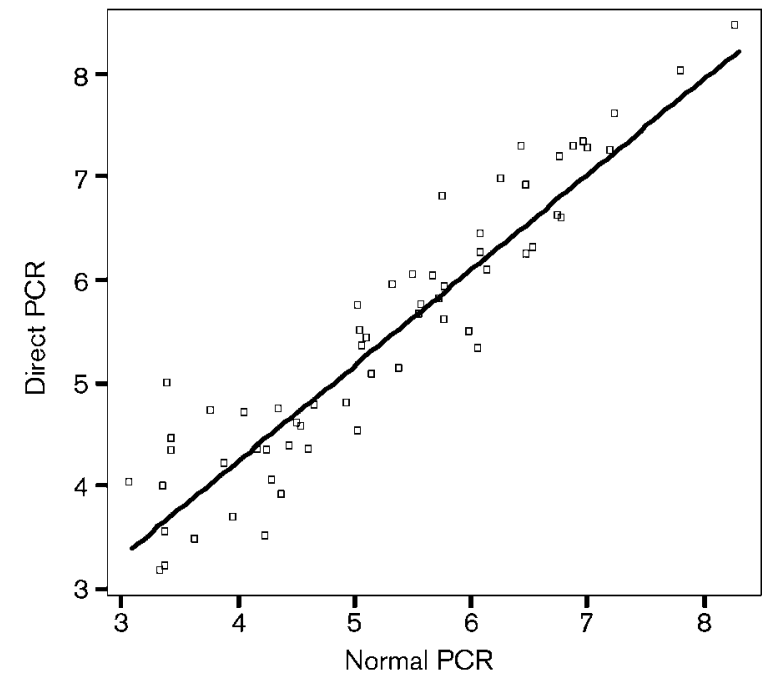

Fig. 4. The relationship between direct $P C R$ and normal PCR. HBV DNA concentrations were log transformed. The time required to perform the direct serum real-time PCR assay was only about $1 \mathrm{~h}$. Comparing direct serum and normal real-time PCR after DNA extraction, we found that the first method saved $1 \mathrm{~h}$. $y=0.53+0.93 \times x . r^{2}=0.86$

target sequence, bound and quenched TaqMan probe will be degraded by Taq polymerase during the extension step of PCR. Probe degradation allows for separation of the reporter from the quencher dye, resulting in increased fluorescence emission following each PCR cycle (Heid et al., 1996). The mechanism by which HBV DNA in intact viral particles can be quantified may be that the HBV particles in the PCR solution release DNA while they are heated during the PCR procedure. Serum proteins are macro biomolecules and may act in one of two ways to interfere with the fluorescence reading. On one hand, they may bind directly to the probe sequence between the reporter and quencher dye, scattering the light emitted from the reporter dye. On the other hand, some proteins may absorb excitation light from the instrument and emit light at a spectrum overlapping that of the reporter dye, raising the initial $\mathrm{F}_{0}$. With the increment of PCR steps, proteins become denatured at high temperatures and may be inclined to form deposits. Deposit particles scatter the excitation light from the instrument, thus little light is absorbed by the reporter dye, yielding little fluorescence. A reporter dye, such as FITC, has a fluorescence excitation spectrum peak at $493 \mathrm{~nm}$ and emission spectrum peak at $525 \mathrm{~nm}$. Bilirubin has an absorption band ranging from 450 to $490 \mathrm{~nm}$, whereas haemoglobin has an absorption band ranging from 510 to $550 \mathrm{~nm}$. So, bilirubin quenches fluorescence by absorbing excitation light from the instrument, whereas haemoglobin quenches fluorescence by absorbing light emission from the reporter dye. Triglycerides may dominantly quench fluorescence by scattering excitation light. However, the exact mechanism of each endogenous substance remains to be further elucidated.

The second derivative maximum method for quantification is automatically determining the $\mathrm{Cp}$ for individual samples. This was achieved by a software algorithm that identifies the first turning point of the fluorescence curve, which serves as the $\mathrm{Cp}$ in this calculation method. Neither baseline adjustment nor crossing line setting is required in this method. The software copes with effects and artefacts such as spikes in the log-linear phase, and noisy plateaus or curves where the plateau phase has not yet been reached. No Cp value will be displayed for a curve with either a slowly increasing or a slowly decreasing fluorescence or a noisy background, which does not allow a considerable fluorescence value to be attained. The second derivative method is a more appropriate method for direct serum real-time PCR, because serum matrix reduced the emitted florescence below the acceptable threshold and, sometimes, the $\mathrm{Cp}$ value could not be obtained by fit point mode. Increased amounts of circulating DNA have been found in a variety of disorders including cancer, autoimmune disease and infection (Sozzi et al., 2003). It has been predicted for years that simplification of detection methods may widen the availability of this type of testing (Lo, 2000). Our study has further demonstrated the validity of direct serum real-time PCR.

In the present study, we showed a high level of concordance between direct serum real-time PCR and classical real-time PCR during HBV DNA quantification. We also demonstrated that this method could be performed on the LightCycler instrument. By omitting DNA extraction and gel electrophoresis, this method allows for substantial labour and cost savings. In conclusion, direct serum real-time PCR is a simple, economical, time-efficient, sensitive and accurate method for the quantification of serum HBV DNA.

\section{REFERENCES}

Castley, A., Higgins, M., Ivey, J., Mamotte, C., Sayer, D. C. \& Christiansen, F. T. (2005). Clinical applications of whole blood PCR with real-time instrument. Clin Chem 51, 2025-2030.

Espy, M. J., Uhl, J. R., Sloan, L. M., Buckwalter, S. P., Jones, M. F., Vetter, E. A., Yao, J. D. C., Wengenack, N. L., Rosenblatt, J. E. \& other authors (2006). Real-time PCR in clinical microbiology: applications for routine laboratory testing. Clin Microbiol Rev 19, 165-256.

Heid, C. A., Stevens, J., Livak, K. L. \& Williams, P. M. (1996). Real time quantitative PCR. Genome Res 6, 986-994.

Higuchi, R., Fockler, C., Dollinger, G. \& Watson, R. (1993). Kinetic PCR analysis: real-time monitoring of DNA amplification reaction. Biotechnology 11, 1026-1030.

leamkhang, S., Riangwong, L. \& Chatchawankanphanich, O. (2005). Detection of tomato yellow leaf curl Thailand virus by PCR without DNA extraction. Mol Biotechnol 31, 233-238.

Kaltenboeck, B. \& Wang, C. (2005). Advances in real-time PCR: application to clinical laboratory diagnostics. Adv Clin Chem 40, 219-259.

Kaneko, S., Miller, R. H., Di Bisceglie, A. M., Feinstone, S. M., Hoofnagle, J. H. \& Purcell, R. H. (1990). Detection of hepatitis B virus 
DNA in serum by polymerase chain reaction: application for clinical diagnosis. Gastroenterology 99, 799-804.

Livak, K. J. \& Schmittgen, T. D. (2001). Analysis of relative gene expression data using real-time quantitative PCR and the $2^{-\Delta \Delta C} \mathrm{~T}$ method. Methods 25, 402-408.

Lo, Y. M. D. (2000). Fetal DNA in maternal plasma: biology and diagnostic applications. Clin Chem 46, 1903-1906.

Powers, D. M., Boyd, J. C. \& Glick, M. R. (1986). Interference Testing in Clinical Chemistry, EP7-P. Villanova, PA: National Committee for Clinical Laboratory Standards.
Quint, W. G., Heijtink, R. A., Schirm, J., Gerlich, W. H. \& Niesters, H. G. (1995). Reliability of methods for hepatitis B virus DNA detection. J Clin Microbiol 33, 225-228.

Schuler, F. \& Dolken, G. (2006). Detection and monitoring of minimal residual disease by quantitative real-time PCR. Clin Chim Acta 363, 147-156.

Sozzi, G., Conte, D., Leon, M., Cirincione, R., Roz, L., Ratcliffe, C., Roz, E., Cirenei, N., Bellomi, M. \& other authors (2003). Quantification of free circulating DNA as a diagnostic marker in lung cancer. J Clin Oncol 21, 3902-3908. 